\title{
UMA METODOLOGIA PARA A PSICANÁLISE
}

\author{
A METHODOLOGY FOR PSYCHOANALYSIS
}

UNA METODOLOGÍA PARA EL PSICOANÁLISIS

Oswaldo França Neto*

\section{RESUMO}

Alain Badiou lamentou a hegemonia contemporânea da álgebra (que lida com números) em detrimento da geometria (que lida com formas e figuras). Seguindo o ideal do cogito cartesiano de recobrimento do ser pelo saber, a ciência tem buscado tudo apreender em termos quantitativos, passível de mensuração. Sabemos também que, classicamente, a universalidade é concebível apenas no apagamento das singularidades. Como pensar, nesse contexto, um sujeito? É possível uma fórmula contemplar conjuntamente o universal (matema) e o singular (a que se refere um sujeito)? Torna-se interessante a progressiva escolha de Lacan em trabalhar com a teoria matemática das categorias que se interessam por setas, ou funçóes, e as deformaçóes que aí se operacionalizam. Poderíamos aventar que Lacan propóe uma metodologia da transformação, ao forçar a ex-sistência do real como terceiro elemento indissociável da consolidada associação científica do saber com a verdade, forçando a subversão do que seriam esses dois últimos termos.

Palavras-chave: ciência; psicanálise; sujeito; topologia; real.

\section{Abstract}

Alain Badiou grieved the contemporary hegemony of algebra (which deals with numbers) over geometry (which deals with shapes and figures). Following the ideal of the Cartesian cogito regarding the Being for Thinking, science has sought to grasp everything in quantitative terms, able to measurement. We also know that, classically, the universality is conceivable only in the deletion of singularities. How should an individual, in this context, think? Is it possible that a formula jointly consider the universal (mathema) and the singular (regarding to an individual)? It is interesting the progressive choice of Lacan in working with

\footnotetext{
* Universidade Federal de Minas Gerais, Belo Horizonte, MG, Brasil.
} 
the Mathematical theory of categories, who is interested in arrows, or functions, and deformations that are operationalized. We could wonder that Lacan proposes a methodology of transformation, when forcing the ex-sistence of real as the third indissoluble element of consolidated scientific association of knowledge with the truth, forcing the subversion of would be the last two terms.

Keywords: science; psychoanalysis; subject; topology; real.

\section{RESUMEN}

Alain Badiou lamentó la hegemonía contemporánea del álgebra (que trata números) en detrimento de la geometría (que trata las formas y las figuras). Siguiendo el ideal del código cartesiano de recubrimiento del ser por el saber, la ciencia viene buscando todo el entendimiento en términos cuantitativos, pasible de mensuración. También sabemos que, clásicamente, la universalidad es concebible sólo en la supresión de las singularidades. ¿Cómo una persona puede pensar, en este contexto? ¿Es posible de una fórmula contemplar conjuntamente lo universal (matema) y lo singular (a que se refiere una persona)? Se torna interesante la progresiva elección de Lacan en trabajar con la teoría matemática de las categorías, que se interesan por las flechas, o funciones, y las deformaciones que ahí se ponen en práctica. Podríamos indicar que Lacan propone una metodología de la transformación, al forzar la ex-sistencia de lo real como tercero elemento indisociable de la consolidada asociación científica del saber con la verdad, forzando la subversión de lo que serían estos dos últimos términos.

Palabras clave: ciencia; psicoanálisis; persona; topología; real.

Freud não se cansava em reafirmar a cientificidade da psicanálise. Mas as resistências por ela provocadas na ciência positivista, seja em sua época, seja contemporaneamente, sempre foram notórias. Como considerar ciência um campo no qual seus objetos, apesar de tematizados à exaustáo, jamais se deixam apreender em sua totalidade, mostrando-se evanescentes e sensíveis a acontecimentos contingentes? O objeto princeps da psicanálise, pelo menos aquele eleito por Lacan e por este nomeado como objeto $a$, se caracteriza exatamente pela sua dessubstancialização, colocando-se não como um dado fenomênico, mas como causa inapreensível do movimento de um sujeito. Se a psicanálise é ciência, e esta tem como uma de suas principais características a prerrogativa de ser detentora de um discurso pretensamente universal, torna-se necessário buscar a formalização de 
um método que seja compatível com o objeto psicanalítico, método este respaldado em algum tipo de referência que seja universalizável em seus desdobramentos.

Alain Badiou, filósofo francês contemporâneo, propõe que a base do pensamento ocidental encontra-se na antiga Grécia, mais especificamente nas elaboraçóes de Platão (Badiou, 1996). Para esse filósofo grego, o ser corresponderia ao mundo das ideias. Ao conceder às ideias um estatuto ontológico, Platão teria deslocado para o segundo plano a nossa apreensão sensível, e, talvez, a própria pertinência da existência ou não dos objetos que nos acostumamos a chamar de naturais, ou pertencentes à natureza. Para Platão, a ciência por excelência teria por fundamento a matemática, por se tratar de campo investigativo restrito à abstração e totalmente desvinculado dos corrompíveis e mutáveis objetos da percepção sensível, passível dessa forma de se propor como realmente universal. A física, por exemplo, seria secundária à matemática, na medida em que ela seria ciência de mundos particulares (Badiou, Milner, \& Petit, 2012, p. 158). Um físico, no seu labor, depende das fórmulas matemáticas, sendo o inverso não verdadeiro. Um matemático, em suas elaboraçôes, prescinde de qualquer experimentação empírica, concebendo suas fórmulas como tendo existência própria, independentemente de sua aplicabilidade ou não na dita natureza.

Mas se para Platáo o objetivo do homem que procura a verdade sobre o ser encontra-se na exploração do mundo das ideias, poderíamos dizer que, nos dias atuais, tendemos a considerar que o objetivo de um bom cientista encontra-se na adequada apreensão dos objetos considerados como naturais, ou que teriam seu funcionamento compatível com aquilo que chamamos de natureza. Haveria, aqui, um deslocamento de importância. Enquanto o filósofo grego formalizava-nos como seres de linguagem, em detrimento de uma objetividade que supostamente nos precederia, um bom cientista do século XXI parte do princípio de que a natureza é o solo objetivo, imutável, de tudo o que existe, estando na sua apreensão o caminho para se chegar à verdade. Da prevalência das Ideias passamos para sua subordinação a uma suposta imutabilidade objetiva do ser.

Alain Badiou propóe um retorno ao mundo das ideias de Platáo. Aos olhos desse filósofo francês, à universalidade é vedada a existência, pois existir é uma categoria local. Forçar a existência de uma universalidade é forçar a apresentação de algo que, por definição, não se pode localizar, não pode se apresentar como mais um dentre outros objetos de um mundo. Segundo Badiou, para que uma existência empírica qualquer possa vir a se marcar por um traço de imutabilidade e eternidade (passível de portar, dessa forma, a característica de ser universal), isso só pode vir a acontecer a partir do forçamento paradoxal de sua apresentação como tendo o estatuto de algo que a princípio poderia apenas ex-sistir (existir 
fora), já que toda existência, por definição, pode se dar apenas localmente, em um mundo particular.

Se o universal estaria no registro da Ideia, e sua existência empírica seria, por princípio, impossível, vemos aqui, em Badiou, a possibilidade do forçamento de sua apresentação como elemento do campo por meio de um acontecimento não apenas inesperado e contingente, mas, sobretudo, não passível de apreensão pelo saber hegemônico. Esse acontecimento impossível se apresenta como singularidade na medida em que entendamos singular como aquele termo que, apesar de se apresentar como elemento de uma dada situação, náo se deixa incluir por qualquer uma de suas classificaçóes (Badiou, 1996, p. 398). Badiou propóe, assim, que a única possibilidade de existência empírica de uma universalidade seria por meio do forçamento impossível de sua localização, passando então a existir como singularidade. $\mathrm{O}$ sujeito seria posterior a essa conjunção impossível, como defesa desse acontecimento paradoxal e subvertedor do saber instituído.

Essa apresentação paradoxal de uma universalidade que se faz existir como singularidade permite-nos distinguir o universal que estamos aqui tratando daquele da ciência ou da matemática. A ciência, ao se propor apreender o que seria eterno e imutável na existência, parte de um engodo que ela faz questão de esquecer (foracluir, dirá Lacan), pois, como dissemos acima, ao eterno é interditada a existência. O Todo é impossível de existir, nos dirá o filósofo e matemático Bertrand Russell (1872-1970) em seu famoso paradoxo. "Mesmo uma proposição matemática não seria intrinsecamente universal", como nos lembra Célio Garcia, “já que depende dos axiomas que a sustentam” (Garcia, 2011a, p. 65).

\section{Ciência}

Se definir ciência não é simples, a posição que esta ocupa na hierarquia de valores nas sociedades em que esse termo existe também longe está de ser consensual. Na civilização ocidental, tributária dos antigos gregos, sua posição é central, a ponto de hoje apenas o que possui o predicado de cientifico poder ser considerado, de maneira quase consensual, como portador de verdade (mesmo que esse consenso não implique em uma definição universalmente aceita nem do que seria ciência, nem do que seria verdade). Aristóteles, que trabalhou com a concepção de que existiria uma diversidade de ciências, apesar de considerar a noção de hierarquia (como a subordinação das ciências "poéticas" às ciências "práticas", e ambas às ciências "teóricas"), considera que a ciência primeira, a do ser enquanto ser, que seria, aos seus olhos, a filosofia, é hierarquicamente da mesma espécie 
que as outras (cf. Lalande, 1993, p. 155). Existiria, assim, aos olhos dele, algo que subsumiria todas essas disciplinas em um mesmo campo, chamado de ciência.

Enquanto psicanalistas, talvez pudéssemos começar entendendo a ciência como sendo o discurso que se propóe isento de singularidades, ou seja, sem sujeito. Como Lacan a definia (ou pelo menos uma de suas formas de falar sobre a ciência), ela seria o discurso onde o sujeito estaria foracluído. Nesse sentido, por se apresentar como não afetada por sujeitos ou singularidades, a ciência se colocaria como passível de transmitir aquilo que classicamente chamamos de universal, depurada do contingente e do corruptível. Ela estaria no campo do Um, mesmo que esse Um seja fragmentado em campos não transitáveis entre si. E essa fragmentação lhe seria inerente, pois os campos científicos, apesar de supostamente não se sustentarem sobre singularidades, se assentam sobre axiomas distintos entre si, estabelecendo campos igualmente distintos. Mas, deslocando um pouco os conceitos, se a ciência como a definiu Lacan, assentada sobre o ser, foracluiria o sujeito e sua singularidade, talvez pudéssemos pensar em variações, aventando a possibilidade de uma ciência do real, em que singularidades viessem, de alguma forma, a participar do campo. Para isso seria necessário desdobrarmos um pouco as relaçóes entre saber, verdade e real, e uma possível distinção entre o real de Lacan e o ser da filosofia.

Saber...

Freud assentou sua ciência sobre a histeria, aquilo que, na sua época, se apresentava como dessaber. Trata-se, aos olhos de Freud, de uma ciência que aposta no dessaber sem, no entanto, abrir mão do saber, já que ela se propóe, ao sustentar o dessaber, a elaboração de um saber que dele (dessaber) adviria. A ciência de um saber por vir, a ser construído. Uma ciência, no dizer de Célio Garcia, do inacabamento, em oposição às ciências do acabamento, que partem da premissa do esgotamento possível, ou desejável, de todo dessaber (Garcia, 2011b, p. 26-27).

O termo inacabamento foi proposto por Jean-Luc Nancy em texto publicado em 2003. Segundo esse autor, Freud seria não o formulador de uma terapêutica, mas um pensador da finitude. À infinitude da consciência Freud teria inscrito uma finitude, que seria o inconsciente. A verdade do pensamento é o inconsciente, estando nele, portanto, a determinação dos limites da consciência. Ao apresentar-se como "o fim da consciência", ou "o fim da significação" (Nancy, 2003, p. 146), o inconsciente seria aquilo que daria ao pensamento o caráter de processo inacabado, condenado ao inacabamento. Tratar-se-ia de uma fini- 
tude infinita, ou, dizendo de outra forma, de uma infinitude localmente situada (Nancy, 2003).

Trabalhando a relação que poderia ser pensada entre a filosofia e a psicanálise, Garcia talvez nos permita pensar, utilizando expressóes similares, a relação entre psicanálise e ciência, já que ambas, filosofia e ciência, seriam igualmente solidárias à ideia de acabamento. Substituindo o termo filosofia pelo de ciência, obteríamos a seguinte frase a partir do texto de Garcia: "se a aproximação Psicanálise e Ciência é possível, não será em termos de subsunção de uma pela outra, mas com esta aproximação buscamos acesso por meios não científicos a um exame das condições de verdade da Ciência"1 (Garcia, 2011b). Para esse autor, à psicanálise caberia um exame das condiçóes de verdade de outros discursos comprometidos com o acabamento.

Para Alain Badiou, que considera a verdade como uma categoria universal, e que parte do princípio de que o Um, ou o Todo não existem, o infinito é uma exigência intrínseca e imanente a qualquer situação e não algo que se coloque como transcendente ao campo da existência (Badiou, Milner, \& Petit, 2012, p. 97). Toda verdade é infinita, estando comprometida com o inacabamento, o que explica a sua universalidade, pois a ela é facultado o trânsito por mundos diversos, na medida em que ela não se deixa limitar (acabar) por nenhum deles. Temos aqui uma universalidade que não se coloca como transcendência, como algo que faria Um de tudo o que existe. Ela é universal não por estabelecer a completude, mas por apresentar-se como não toda, não se deixando constranger por classificação alguma, passível assim de extrapolar as classificações estabelecidas e apresentar-se em não importa qual mundo particular. Uma universalidade que se apresenta, paradoxalmente, de forma imanente.

Já a ciência, assim como a filosofia, tem a pretensão ao acabamento. Não se trata assim de incluir a psicanálise no rol das ciências, uma dentre todas, mas de tentar apreender o que de subversão a "ciência" criada por Freud produz sobre as outras ciências.

\section{Verdade...}

$\mathrm{Na}$ medida em que a ciência se propóe ao universal, para Lacan, como vimos acima, ela classicamente foraclui a verdade singular que estaria na sua gênese. Poderíamos dizer que ela se apresenta como uma letra que se escreve no real, ou, nos termos que estamos trabalhando aqui, uma função do saber sobre o real, pela qual a verdade de um sujeito estaria foracluída. Enquanto psicanalistas, ao considerarmos o pensamento como sendo a preservação produtiva na consistência 
do saber de sua gênese inconsistente, podemos propor a ciência como um pensamento dedutivo, desdobramento no simbólico quando de sua afetação pelo real, mesmo que a verdade do que a causa se mantenha em suspensão, ou, utilizando termos de Lacan em "A ciência e a verdade" (Lacan, 1998), se mantenha como causa formal. Nesse texto de Lacan, aos olhos de Miller, poderíamos substituir no título o termo verdade pelo termo psicanálise (Miller, 1993). A ciência estaria do lado do saber e a psicanálise do da verdade, estando a conjunçáo dos dois no sujeito cartesiano.

Para Miller, ao longo do ensino de Lacan a psicanálise deixa de contestar a ciência e passa a colocar-se na sua escola, "na medida em que a ciência visa o saber presente no real" (Miller, 1993, p. 3). Ou seja, a ciência, em relação ao real, lida com o que nele é saber.

Se Lacan fez uso das matemáticas, ou seja, se ele fez uso da ciência na tentativa de estabelecer o universal de sua teoria, não há uma coincidência entre psicanálise e ciência, já que o tema princeps sobre o qual se debruça a psicanálise é o sujeito. Ela tem como visada exatamente aquilo que a ciência foraclui para poder se manter no campo do que ela considera como sendo universal.

Real...

Ao considerar que a experiência pode ser controlada, e, a partir de então, explicitada por meio da linguagem, a ciência que classicamente nos serve de referência está pressupondo não apenas uma previsibilidade no ser, mas também que a determinação deste é compatível com as ferramentas lógicas do nosso pensamento. Trata-se de uma concepção de universo que se baseia no pensamento construtivista, que parte do princípio de que, sob a jurisdição da língua, o excesso pode ser reduzido ao mínimo e ao funcionamento do ser podemos sobrepor a lógica de funcionamento da linguagem (Badiou, 1996).

Propor uma ciência do ser em contraposição a uma ciência do real, a primeira centrando-se no saber (mesmo que considerando-nos impotentes, por nossas limitaçóes, em vir a tudo saber), e a outra no impossível ao registro do saber, pede uma diferenciação entre ser e real. Para Badiou, o ser seria um termo da filosofia, termo este que ocuparia lugar central nessa disciplina (Badiou, 1999a). O objeto primordial da filosofia desde seu nascimento grego seria apreender, por meio do saber, o que seria o ser, ou aquilo que persiste imutável e eterno, em oposiçấo aos objetos transitórios e corrompíveis que com lidamos cotidianamente. Caberia à filosofia buscar a fidedigna definição sobre o ser, cernindo-o com as ferramentas do saber, mesmo que seu conceito se dirigisse em situá-lo como o que 
se coloca para além do saber. Kant, por exemplo, propôs definir das Ding como aquilo que se mantém exterior à capacidade do conhecimento. Ou seja, em não importa qual definição, mesmo aquela que o situa como exterior, a filosofia sempre buscou cernir o ser tendo como ponto de visada o saber. Já o real de Lacan se define exatamente por se colocar, frente ao saber, como paradoxal. Do real tanto sabemos, como não sabemos. Assim como dele podemos fazer uma escrita, ele se coloca como impasse à escritura. O real, ao mesmo tempo saber e impossível ao saber, desconstitui o campo do conhecimento sábio, apresentando-se nele como o ponto de inconsistência que teve necessariamente que ser excluído para que a consistência pudesse se constituir.

$\mathrm{Na}$ ciência do ser, o infinito é visto como impotência, ou seja, não podemos atingir o Todo por sermos limitados em nossa capacidade de compreensão, e por este poder crescer potencialmente de forma infinita. Já na ciência do real, o infinito apresenta-se como impossibilidade não por impotência nossa, mas por se tratar de algo paradoxal ao saber, encontrando-se na gênese, como causa $a$ priori, de todos os desdobramentos. Se na ciência do ser o infinito encontra-se à frente, inalcançável por crescer infinitamente, na ciência do real o infinito está na origem, como ponto de inconsistência que apresenta-se como causa de todo e qualquer campo de saber.

\section{Saber/Verdade/Real}

Se a matemática foraclui sua singularidade, nem por isso esta deixa de ser, na fundação, aquilo que provoca a sintaxe que se estabelece. Porém, enquanto ciência, esse ponto original passará a se fazer presente não mais como singularidade, mas como axioma. Temos aqui as fórmulas, que se colocam como letras apriorísticas, depuradas de questionamentos e portadoras de universalidade absoluta, a quem seriam facultadas a transmissão integral. Caberia à matemática a exclusiva detenção do título de guarda da univocidade, colocando-se como "paradigma de toda penetraçáo da verdade na mediocridade do sentido" (Badiou \& Cassin, 2013, p. 62). Mesmo, porém, nelas ausentificando-se o sujeito, tornaram-se as fórmulas uma ferramenta fundamental nas elaboraçôes de Lacan, dessa vez sob a forma dos matemas. Esses se apresentam, apesar de fórmulas, como impasse ao matematizável:

Há o real, há o que do real se ensina (o matematizável), há o matema como impasse do matematizável. É aí que a vocação arquicientífica do ato (no sentido de Lacan) se mostra. Pois se o ato se encontra no ponto do mate- 
ma (do saber transmissível), persiste o fato de que o matema faz real (ou impasse) do real ensinável (o matematizável). Ele é, pois, o matema, para além do matemático. Ele pode surgir como o que fixa um real do real. Um real passível de inscrição do real ensinado. O matema é o que inscreve, como impasse, o real daquilo que do real se ensina (Badiou, 1999b, p. 59).

Se o matema lacaniano pode ser entendido como função do real no saber, teríamos a acrescentar que ele "refere-se afirmativamente à ausência", pois o que é integralmente transmissível é a inscrição da ausência de sentido, não propriamente como o vazio do sem sentido, mas sob a forma de uma afirmaçáo, de um dizer positivo que se apresenta como "senso ab-sexo" (Badiou \& Cassin, 2013, p. 68). Os matemas, para um psicanalista, têm serventia apenas quando se faz existir neles o que neles inexistiria se nos mantivéssemos a concebê-los como puras fórmulas matemáticas. Um matema, em si, é pura associação de letras. É apenas na sua manipulação que, caso a caso, um sujeito específico faz com que aquela fórmula venha a se produzir, para ele, como portadora de sentido. $\mathrm{Na}$ medida em que nos colocamos a manipulá-los, percebemos que nem tudo se reduz a sua literalidade. Como diz Célio Garcia ao falar da novidade que os jovens em conflito com a lei podem nos oferecer no seu manuseio irreverente do estabelecido, "o saber é saber a ser inventado, a partir do que ele sabe; ele se serve da analogia, não de fórmulas; exige criatividade" (Garcia, 2011b, p. 26). No SELEX², onde Garcia pôde observar esses jovens, as mesmas sagradas fórmulas utilizadas pelos engenheiros em suas elaborações eram profanadas por esses adolescentes infratores, permitindo, com essa dessacralização, um uso agora não mais restrito à pura dedução, podendo a criatividade ser convocada.

Para desdobrar esse tema, Garcia propóe contrapormos o Geist de Hegel ao Witz de Freud, o primeiro formando pares, tais como saber/verdade, o segundo se apresentando como solução subversiva, "agente de uma outra forma de laço social (saber, verdade e real são inseparáveis)" (Garcia, 2011b, p. 18). Hegel, como todo bom filósofo, trabalha formando pares, permanecendo assim no campo da consistência. A novidade trazida por Lacan, explicitada em seu texto "O aturdito" (Lacan, 1972/2003), é que "o tripleto saber-verdade-real não pode ser segmentado. Não pode ser distribuído em pares” (Badiou \& Cassin, 2013, p. 74). O problema, porém, reside exatamente nessa não segmentação, pois é logicamente impossível a associação, ao mesmo tempo, desses três termos. Podemos pensar associações dois a dois (saber/verdade, saber/real, verdade/real), mas não os três concomitantemente. Lacan teria nos pontuado onde filosofia e psicanálise se distinguem, a primeira preservando-se em associaçóes dois a dois, a segunda 
apostando em uma coexistência impossível, forçando a existência de algo que só pode inexistir.

A teoria matemática das categorias (onde se inclui a topologia), ao falar de funções e não de objetos estáveis, possibilita um manuseio interessante dessa dificuldade. Se efetivamente podemos dizer que não há saber do real, nem por isso estamos errados em considerar uma função do real no saber. Também no que concerne à verdade e ao saber, se não há saber da verdade, podemos, no entanto, falar na existência da verdade de um saber desde que um real nele funcione - " a verdade de um saber se mede no fato de que algo do real do senso ab-sexo venha a funcionar nele" (Badiou \& Cassin, 2013, p. 74). Ao contrário da filosofia, não podemos abrir mão da indissociabilidade saber-verdade-real. A psicanálise, nesse sentido, não se colocaria como uma ciência, uma filosofia ou outros campos com os quais ela se esfrega, mas como um Witz na relação com esses campos, na produção impossível de um sentido que só se pode dar no ab-senso.

\section{Matemática e lógica}

As relaçóes entre os campos com os quais estamos lidando nem sempre são simples. A matemática, por exemplo, que para Platão está no fundamento da ciência por excelência, que relação teria com a lógica? Seria de disjunção? Ou será de conjunção? Alain Badiou, em um dado momento, propóe uma distinção, considerando que a matemática seria o discurso ontológico por natureza (Badiou, 1996, p. 21), por ter como objeto o ser (mesmo se este se apresente nela como foracluído). A lógica, por sua vez, seria a ciência do real (Badiou, 1996, p. 13), e, ao contrário das matemáticas, seria sem objeto (ou, pelo menos, este não se identificaria com o $\operatorname{ser}^{3}$ ). Mas essa distinção nem sempre é clara. A topologia, que entenderíamos no campo da lógica, faz parte da teoria das categorias, que é um dos ramos das matemáticas. Talvez mais do que conjunção ou disjunção, fosse interessante trabalharmos esses dois campos (matemática e lógica) em termos de função, desdobrando o que de uma se projeta sobre a outra.

A topologia, se incluída no campo das matemáticas, nela, no entanto, não nos restringimos à dedução, mas somos invocados também a induções e ao manuseio de "tensóes, relaçóes de valor positivas e negativas, fortes e fracas" (Abascal $\&$ Bilbao, 2011, p. 6). A topologia poderia ser entendida como um contraponto ao estruturalismo, ao possibilitar o movimento, a historicidade, em oposição à pura sincronia. De certa forma, estaríamos remetidos a duas concepçóes de ciência: uma trabalhando com o que se preservaria estático ou imutável, outra com 
deformaçôes e transformaçóes (mesmo se a tentativa de se apreender esses movimentos passe pelo desejo de cernir a sintaxe das relaçóes, ou aquilo que permaneceria invariante, qualitativamente, ao longo das deformaçóes que se processem). $\mathrm{Na}$ topologia, o que interessou especialmente a Lacan foram as superfícies não-orientáveis, aquelas que propiciavam momentos de corte ou ruptura, em que o resultado não faz "duas partes: duas partes a serem denotadas pelo sim e pelo não" (Lacan, 1972/2003, p. 474).

$\mathrm{O}$ interessante nesses cortes é a ambiguidade que carreiam pela impossibilidade de sua plena localização. Eles "têm efeito de subversão topológica" (Lacan, 1972/2003, p. 474), e a banda de Moebius é a demonstração, reduzida ao osso, desses pontos a princípio impossíveis de demonstrar nas deformaçôes dos objetos topológicos, pontos onde ruptura e permanência se identificam. $\mathrm{Na}$ garrafa de Klein, por exemplo, se em um dado momento da inflexão somos forçados a um corte na superfície, ao reduzirmos esse movimento à banda de Moebius obtemos uma transformação que não se operacionaliza fenomenicamente como corte, apesar de este poder se apresentar como fato quando se leva em conta dois pontos distintos do movimento ${ }^{4}$.

Uma boa ilustração desse movimento em que determinada mudança qualitativa se apresenta como um contínuo e não como ruptura podemos encontrar no conto "Meu tio o iauaretê" de Guimarães Rosa (Rosa, 1962). Nesse interessante conto, a partir de um momento da transformação do caçador ("onceiro") em onça, não nos autorizamos mais a dizer estarmos lidando com um homem, mas sim com o felino. Nesse momento final, porém, apesar de ele se apresentar como ruptura em relação ao início do processo, não podemos cernir com as mãos o ponto exato do corte (ou ruptura) nesse processo de deformação contínua. Esse ponto inapreensível, (des)localizado, seria o que chamamos de singularidade. $\mathrm{O}$ singular existe "na ausência do especificado", surgindo, em sua existência, "como absoluto, desinteressado, para além de qualquer negociação ou discussão" (Garcia, 2011a, p. 56). Em termos psicanalíticos, seria a possibilidade de operarmos "subtraindo ao analisante o imperativo de gozo" (Garcia, 2011a, p. 55), mantendo-o a salvo do real identitário e suas segregações.

Badiou propóe trabalharmos com a concepção de diferença mínima, que nos permitiria abordar a questão da diferença e das transformaçôes sem passar necessariamente por cortes ou rupturas (Badiou, 2007). Diferentemente da lógica do significante, adaptada para uma clínica descontinuísta, o modelo topológico se presta bem para examinar passagens, transformaçóes, nas quais a descontinuidade, tratada agora pela diferença mínima ("ponto de indecidibilidade máxima que apaga todo o contorno" (Garcia, 2011a, p. 100)), permitir-nos-ia, por exem- 
plo, pensar no que poderíamos chamar de uma clínica continuísta, na qual a diferenciação entre neurose e psicose se complexificaria, deslocando-nos de um puro binarismo.

\section{Universal (para todos/náo todo)}

Nessa refrega entre psicanálise e ciência, pode ser interessante um recente debate entre Alain Badiou e Jean-Claude Milner (Badiou, Milner, \& Petit, 2012).

Milner propõe que as concepçóes diferentes entre ele e Badiou são resultado de uma diferença de método, similar ao que diferenciaria a linguística da matemática. Milner, enquanto linguista, trabalha com uma concepção de ciência que nos concebe como prisioneiros de uma caverna:

Nós nos voltaremos, ao que nos concerne, à diferença de método. Ela é fundamental. Como já disse, considero que não saímos da caverna. Isso vem certamente de meu passado de linguista, já que a linguística, enquanto ciência, não pode sair das línguas enquanto tais: ela é o que chamo uma ciência "cavernicole", por oposição à matemática (Badiou et al., 2012, p. 157)5.

No sentido aqui proposto por Milner, linguística e matemática assentar-se-iam sobre concepçóes distintas de universalidade. Poderíamos dizer que em ambas as concepçóes existiria uma exceção que constitui a perspectiva de um para todos. Na linguística, porém, essa exceção, se realmente existente (já que não teríamos como provar sua existência), fica do lado de fora, inalcançável, garantindo, com sua exterioridade, a existência do Um e da perspectiva do Todo para aquele mundo particular. Para Jean-Claude Milner toda e qualquer universalidade que possamos acessar é sempre concernente, e restrita, ao mundo em que vivemos. Não há qualquer possibilidade de sairmos da caverna, estando nossa visão confinada às particularidades do mundo em que estamos inseridos. A segunda concepção, a da matemática, em que entenderíamos Badiou, essa exceção é imanente. Aqui, a exceção não faz Um, e o para todos seria concebível apenas em um devir a rigor inapresentável em si, já que ele se apresenta como lançamento, na origem, na forma de um não todo, ou de um excesso constitutivo. No universal não todo, "a dimensão do para todos não é suposta desde o início, pois o sujeito se põe a trabalho em sua singularidade. O caminho para se chegar até o para todos será alcançado graças à efetuação (um por um) de verificação dessa singularidade" (Garcia, 2011a, p. 65). 
Se consideramos a propriedade de ser universal uma das características da ciência, náo podemos nos esquecer, como nos lembra Célio Garcia, que podemos encontrar em Lacan duas figuras do Universal: o todo e o náo todo (Garcia, 2011a, p. 63). A concepção que se baseia no todo, na qual situaríamos de bom grado o para todos que a nossa noção tradicional de universalidade carreia, está em consonância com o Um, conjunto fechado, "construído a partir de uma exceção que fica de fora, segregada" (Garcia, 2011a, p. 63). O segundo universal de Lacan, aquele que chamamos de não todo, é mais difícil de ser apreendido. Ele, na verdade, não se mostraria passível de apreensão, mas apenas de uso ou experimentação, na medida em que seu para todos se daria como promessa em um devir a rigor impossível de se apresentar, efetuando-se no território, localmente, por meio de uma exceção imanente. Nas palavras de Garcia, e tendo como referência o "procedimento genérico" proposto por Alain Badiou (Badiou, 1996), na dimensão do não todo "temos que admitir que o universal (para todos) advém como singularidade, e que temos no início do universal (para todos) a precariedade de um suplemento do tipo excęão que garante. Se o universal, aqui, vale para todos, será precisamente na medida em que a inscrição não depende de nenhuma determinação em particular" (Garcia, 2011a, p. 64).

Propomos, assim, que, caso fôssemos aventar uma cientificidade à psicanálise, deveríamos pensar em uma universalidade que, ao invés de se referenciar em um para todos que se apresenta como exterior à caverna, se apresentaria como furo no campo do universal todificado. Teríamos que pensar um para todos que se inscreve como exceção imanente à lógica universalizante do próprio para todos almejado. Uma inscrição suplementada por uma exceção que garante sua indeterminação em relação a qualquer predicação. De um universal garantido pela predicação, e portanto apreensível enquanto conjunto fechado, teríamos agora que nos haver com uma universalidade que se apresenta como ponto de inconsistência, uma localização infinita, que se garantirá como universal enquanto conseguir se apresentar e ao mesmo tempo manter-se em exclusão a qualquer determinação que a classifique como parte de um Todo unificado, viabilizando que sua existência não fique confinada à predicação de um mundo particular. Mesmo se apresentando como elemento de um mundo, ao resistir ao encarceramento das classificaçóes ele se preservaria como universal, podendo vir a se apresentar como elemento de mundos (cavernas) diferentes, preservando-se assim como uma via de acesso contingente à universalidade.

Badiou e Milner, cada qual a sua maneira, não compactuam com o ideal da ciência de um universal para todos que englobaria todos os mundos (ou cavernas). Segundo Milner, enquanto prisioneiros da caverna, para nós esse universal não 
existiria, ou, se existir, não pode ser acessado. Cada mundo, apesar de contingente, nos enclausuraria em suas particularidades, o que tornaria impossível sair-se do il y a. Para Milner, nós somos prisioneiros do il y a de nossa própria caverna. Qualquer saída seria conceber a possibilidade de se acessar uma transcendência externa, o que nos é interditado. Para Badiou, a saída da caverna é possível não por meio de uma exceção transcendente, mas por meio de uma exceção imanente, uma universalidade que escapa às particularidades de qualquer mundo por não se deixar apreender por suas predicações.

$\mathrm{Na}$ concepção cavernosa de Milner, ao se buscar o universal busca-se a referência que seria comum a todos os elementos da caverna da qual somos prisioneiros. Para ele, esse é o único universal passível de ser acessado. Já na concepção proposta por Badiou, de "saída" da caverna, ao se buscar o universal busca-se aquilo que, mesmo apresentando-se como elemento da caverna, estaria nela em estado de exceção por não se deixar limitar por qualquer classificação proposta pelo saber hegemônico, extrapolando dessa forma os limites da própria caverna. Trata-se, nessa segunda acepção, de uma universalidade que se dá de forma imanente e que, ao invés de fazer Um de todos os elementos da caverna, esmaece a própria capacidade daquele mundo em particular de garantir suas classificaçóes, provocando uma subversão daquilo que nele se apresenta como limite.

\section{Metodologia da transformação}

Em oposição a uma metodologia em que os passos são definidos a priori, gostaríamos de aventar que Lacan propóe, com seus trabalhos, uma metodologia da transformação. Nesse sentido, podemos nos aproximar das pesquisas do antropólogo Viveiros de Castro e do que ele nomeou por perspectivismo ameríndio. Esse pesquisador brasileiro propóe que, para os índios do continente americano, o que interessa não são os objetos pretensamente estáveis que estariam na origem ou no final de determinado processo, mas os caminhos, ou as transformaçóes, que se operacionalizam no percurso.

Contra a solidez, a exatidão e a rigidez dos muros ocidentais, o perspectivismo ameríndio apresenta a porosidade dos limiares, a tenuidade das fronteiras. Em sua inconstância, aproxima polos e destaca as rachaduras e os buracos das muralhas, questionando a própria formação dessas muralhas, que aos poucos vão se descobrindo disformes, gelatinosas, curvilíneas e múltiplas, ganhando mobilidade e viscosidade. Dessa maneira, os binô- 
mios náo apenas podem se justapor como se multiplicar infinitamente, perdendo seu caráter binário. Contra nossas identidades domesticadas, este pensamento chamado selvagem propóe singularidades e pluralidades; contra nossas classificações estáticas e irredutíveis, sugere metamorfoses, seres em constante transformação, troca, relação (Cernicchiaro, 2010).

O perspectivismo ameríndio propõe que os índios do nosso continente partem não do que é idêntico, mas da diferença. Viveiros de Castro considera que, ao renunciarem às identidades, há neles uma abertura em direção a outros pontos de vista, a outros devires, que para nós seriam interditados. No outro eles não buscariam um espelho, mas uma visão alteritária de si mesmo e uma incorporação dessa alteridade. $\mathrm{O}$ canibalismo presente na cultura indígena, apesar de não efetivamente praticado por todos, não seria uma acumulação de vidas ou substituição de uma vida por outra, mas um devir-outro, no qual o que se perde é a concepção de uma identidade estável, persistente ao longo do tempo. Não existiria para eles uma separação entre a cultura, repleta de humanos idênticos a si, e a natureza, lugar do inumano. Para um índio tudo é potencialmente humano, inclusive os objetos, dependendo de onde estiver o ponto de vista. Poderíamos aqui ver ressonâncias da teoria matemática das categorias, tão explorada por Lacan por meio da topologia. Nesta, o que interessa são as setas, ou funções, e as deformaçôes (especialmente as impossíveis, que foram as que mais interessaram a Lacan) que nelas se operacionalizam. Badiou, em sua teorização sobre a verdade, parece compartilhar dessa lógica, ao propor que:

uma verdade não é um julgamento. Nós não estamos na teoria clássica da verdade como julgamento que corresponde ao real, proposiçáo que é adequada ao real. Nós não estamos na teoria da verdade como adequaçáo, adequação do pensamento do real, etc. Nós estamos na ideia da verdade como processo, que desenvolve, que constrói as consequências de um traço de um acontecimento (Badiou, 2008).

\section{Referências}

Abascal, E. H. S., \& Bilbao, C. A. (2011). Arquitetura e ciência - topologia e intencionalidade em projeto, fronteiras. Arquitextos, 137.01. Recuperado em abr. 19, 2013, de <http://www. vitruvius.com.br/revistas/read/arquitextos/12.137/4091>.

Badiou, A. (1996). O ser e o evento. Rio de Janeiro: Jorge Zahar. 
Badiou, A. (1999a). Lacan e o real. In C. Garcia (Ed.), Conferências de Alain Badiou no Brasil (pp. 67-76). Belo Horizonte: Autêntica.

Badiou, A. (1999b). Lacan e a filosofia. In C. Garcia (Ed.), Conferências de Alain Badiou no Brasil (pp. 55-66). Belo Horizonte: Autêntica.

Badiou, A. (2007). O século. Aparecida: Ideias \& Letras.

Badiou, A. (2008). Introduction à L'Être et l'événement et à Logiques des mondes. Conferência na Université Technique Nationale d'Athènes, Grécia. Recuperado em 19 de abril, 2013, de <http://www.entretemps.asso.fr/Badiou/Athenes.htm>.

Badiou, A., Milner, J.-C., \& Petit, P. (2012). Controverse, dialogue sur la politique et la philosophie de notre temps. Paris: Seuil.

Badiou, A., \& Cassin, B. (2013). Não há relação sexual: duas liçôes sobre "O aturdito" de Lacan. Rio de Janeiro: Jorge Zahar.

Cernicchiaro, A. C. (2010). Perspectivismos. Sopro, 22, 4-6. Recuperado em 19 de abril, 2013, de <http://culturaebarbarie.org/sopro/verbetes/perspectivismos.html>.

Garcia, C. (2011a). Psicologia jurídica, orientaçâo para o real. Belo Horizonte: Ophicina de arte $\&$ prosa.

Garcia, C. (2011b). Psicanálise como Ciência do seu próprio fim, ou o que fizemos com a Psicanálise? Estudos lacanianos, 4(7), 17-28.

Lacan, J. (1998). A ciência e a verdade. In J. Lacan, J. Escritos (pp. 869-892). Rio de Janeiro: Jorge Zahar.

Lacan, J. (2003). O aturdito. In J. Lacan, Outros escritos (pp. 449-497). Rio de Janeiro: Jorge Zahar. (Trabalho original publicado em 1972)

Lalande, A. (1993). Vocabulário técnico e crítico da filosofia. São Paulo: Martins Fontes.

Miller, J.-A. (1993). Sobre o transfinito. Opção lacaniana - Revista Brasileira de Psicanálise, 1(6), 1-5.

Nancy, J.-L. (2003). Das unendliche ende der psychoanalyse. L'animal. Litteratures, arts et philosophies, 14/15, 145-151.

Rosa, J. G. (1962). Meu tio o iauaretê. In J. G. Rosa, De estas histórias. Rio de Janeiro: José Olympio.

\section{Notas}

1 "se a aproximação Psicanálise e Filosofia é possível, não será em termos de subsunção de uma pela outra, mas com esta aproximaçáo buscamos acesso por meios não filosóficos a um exame das condiçôes de verdade da Filosofia” (Garcia, 2011b, p. 17) .

${ }^{2}$ SELEX (Sistemas Elétricos Experimentais): Projeto de extensão do curso de Engenharia de Sistemas da UFMG, visando à ressocialização de jovens em conflito com a lei. 
${ }^{3}$ A "sutura ao ser (vazio)" é o "ponto em que as matemáticas se desvinculam da lógica pura" (Badiou, 1996, p. 14).

${ }^{4}$ A redução do corte que se observa na garrafa de Klein à transformação contínua da banda de Moebius pode ser vista no vídeo a seguir: <http://www.youtube.com/watch?v=BQayK3xtN-8>. 5 "Nous em revenons, nous concernant, à la différence de méthode. Elle est fondamentale. Comme je l'ai déjà dit, je considère que l'on ne sort pas de la caverne. Cela vient sûrement de mon passé de linguiste, puisque la linguistique, en tant que science, ne peut pas sortir des langues telles qu'elles sont: elle est ce que j'appelle une science "cavernicole", par oposition à la mathématique" (Badiou et al., 2012, p. 157).

6 “[...] une vérité ce n'est pas un jugement. Nous ne sommes pas dans la théorie classique de la vérité comme jugement qui correspond au réel, proposition qui est adéquate au réel. Nous ne sommes pas dans une théorie de la vérité comme adéquation, adéquation de la pensée du réel, etc. Nous sommes dans l'idée de la vérité comme processus, qui développe, qui construit les conséquences d'une trace d'un événement" (Badiou, 2008).

Recebido em 4 de junho de 2013

Aceito para publicação em 05 de março de 2014

DOI: $10.1590 / 0103-56652015000100011$ 
